\title{
Surveying Mutation of FLT3 Genes in Children with Acute Leukemia
}

\author{
Maryam Sheikhi ${ }^{1}$, Farhad Zaker ${ }^{2}$, Gholamreza Javadi ${ }^{1}$, Mehrdad Hashemi ${ }^{1}$, \\ Farnaz Razmkhah ${ }^{1}$, Abolfazl Movafagh ${ }^{3}$
}

${ }^{1}$ Department of Molecular Genetics, Tehran Medical Sciences Branch, Islamic Azad University, Tehran, Iran. ${ }^{2}$ Department of Hematology, Iran University of Medical Science, Tehran, Iran. ${ }^{3}$ Department of Medical Genetics, Cancer Research Center, Shohada Hospital, School of Medicine, Shahid Beheshti University of Medical Science, Tehran, Iran.

\begin{abstract}
Background and purpose: Mutation of FMS like tyrosine kinase (flt3) gene causes uncontrolled proliferation of leukemic cells and a bad prognosis. The present study is aimed at implementing molecular tests to diagnose and screen the mutations in acute leukemia patients. Methodology: Totally, 91 children with acute myeloid leukemia (AML) and acute lymphoid leukemia (ALL) were examined as to flt3 mutation, internal tandem duplication (ITD) mutation, and point mutation in exon 17 (e17). ITD mutation in flt3 receptor was carried out in exon $12 \& 12$ and intron 11. As to point mutation in e17, PCR products of the subjects after PCR on genomic DNA of them were examined using restriction enzyme (ECORV) and restriction fragment length polymorphism (RFLP). As to ITD positive, sequencing method was used. Findings: ITD mutation was observed in seven (7.7\%) of acute leukemia patients and two $(2.2 \%)$ patients were diagnosed with point mutation D835. Distribution in different subgroups of FAB was not identical. Conclusion: FLT3 mutation was highly prevalent in children with acute leukemia. Therefore, molecular diagnosis of these mutation, regardless of FAB categorization and before initiation of intervention, can be used to make better decision about therapeutic protocol.
\end{abstract}

Keywords: Acute leukemia- FLT4 gene- ITD mutation- point mutation D835

Asian Pac J Cancer Care, 2 (1), 7-10

\section{Introduction}

Flt3 receptor gene is an extracellular receptor and primitive hematopoietic progenitor, which is belonged to receptor tyrosine kinase III (RTKIII). It is comprised of five extracellular immune-globin like (Ig-Like) regions and one intracellular kinase region and these two are connected through a permeable membrane. Flt3 receptor gene is a 993 amino acid protein $[1,2]$. This gene is positioned on the short arm of chromosome 13 $(13 q 12,2)$ and expressed in immature hematopoietic cell, placenta, gonad, and the brain [3]. Flt3 ligand (FL) is also expressed in most of cell lines [4-5]. Normally and despite stimulation by flt 3 receptors, even ligands cannot induce growth independently from this cells, while it can induces proliferation independent from IL-3 factor of cell in mutated form like ITD or point mutation (D835)
Submission Date: 11/15/2016 Acceptance Date: 01/18/2017

[6]. Despite considerable variation along amino acids replication at the range of 3-50 amino acids, there is no difference in biological activity of flt3/ITD alleles in cell culture or animal models [7-8]. Cooperation between flt 3 mutation and genetic rearrangement may be needed for development of AML phenotype.

Excessive expression of flt 3 reception gene happens in $70-100 \%$ of AML and notable percentage of ALL [9-16]. Mutation in flt3 receptor gene is featured with largest frequency of genetic disorders in AML and the most renowned mutation is ITD with mutation point at ASP835 [10-11].

ITD mutation occurs in exon $11 \& 12$ and intron 11 and the first case of ITD at juxtamembrane (JM) was reported by Nakao et al. (1996). This mutation represents about $20-25 \%$ of AML cases. D835 point mutation also occurs in exon 17 of flt 3 receptor gene and at aspartic

Corresponding Author:

Dr. Abolfazl Movafagh

Department of Medical Genetics, Cancer Research Center, Shohada Hospital, School of Medicine, Shahid Beheshti University of Medical Science, Tehran, Iran.

Email: movafagh.a@sbmu.ac.ir 
acid 835- amino acid. Substitution ASP835Tyr is the most common case [12]. As recommended by the data, about $30 \%$ of AML patients demonstrate acquired mutation in flt 3 receptor gene, which consists of $24 \%$ ITD and 6-7\% point mutation at aspartic acid 835 . Total frequency of the mutation in the adults with AML is $24 \%$ and this figure in children ranges from $10 \%$ to $15 \%$. In other words, frequency of the mutation increases with age and frequency of ITD in ALL is lower and about 1-5\%. Therefore, and given the statistics of mutation of other genes, flt 3 receptor is the most common mutated gene in AML patients [13].

Given the importance of mutation prognosis value of flt 3 receptor gene in AML patients, a great deal of attention has been drawn to development of drugs to suppress flt3 activity.

Taking into account paucity of studies on this type of mutation in Iran, it is necessary and essential to develop methods for screening activation mutation, implement molecular diagnosis methods, and survey expression frequency of the mutation in acute leukemia patients along with the mutations observed in tyrosine kinases or other downstream factors effective on the mutation in acute leukemia cases.

\section{Materials and Methods}

Mutation of flt3 receptor gene in 91 children with AML with different FAB categorization groups (AML-M3 in particular) and ALL with immunophenotype categorization were examined through flow cytometer as a basic study. Blood samples were supplied from blood ward of Aliasghar Hospital, Bahrami Hospital, Children Clinic, and flow cytometer center of Iran Blood Transfusion Organization. Extraction was done through proteinas $\mathrm{K}$ and saturated ammonium acetate. Blood vails were kept in a freezer until DNA extraction. To diagnose ITD mutation genomic DNA was extracted by Forward Primer5'-GCAATTTAGGTATGAAAGCCAGC-, reverse primer5'-CTTTTTTGACGGCAACCTCA GCA, and initial denaturation $1 \mathrm{x}$ based on $\mathrm{PCR}$ program $\left(95^{\circ} \mathrm{C}, 5 \mathrm{~min}\right)$, annealing $\left(66^{\circ} \mathrm{C}, 1 \mathrm{~min}\right)$, denaturation $\left(95^{\circ} \mathrm{C}, 1 \mathrm{~min}\right), 35 \mathrm{x}$ elongation $\left(72^{\circ} \mathrm{C}, 90 \mathrm{~s}\right)$, and final elongation $\left(72^{\circ} \mathrm{C}, 7 \mathrm{~min}\right)$. Mutation cases were detected using direct observation and comparing bands and markers.

As to point mutation D835, reverse primer5'GCAGCCTCACATTGC CCC-3', forward primer 5'-CCG CCA GGA ACG TGC TTG-3', and initial denaturation (12) following $1 \times$ PCR program $\left(95^{\circ} \mathrm{C}, 5 \mathrm{~min}\right)$, annealing $\left(60^{\circ} \mathrm{C}, 1 \mathrm{~min}\right)$, denaturation $\left(95^{\circ} \mathrm{C}, 1 \mathrm{~min}\right), 35 \mathrm{x}$ elongation $\left(72^{\circ} \mathrm{C}, 90 \mathrm{sec}\right)$, and final elongation $\left(72^{\circ} \mathrm{C}, 7 \mathrm{~min}\right)$ were used on the cultured genome extracted from the patients and mastermix including $5 \mu$ buffer, $1 \mu \mathrm{L}$ dNTP, $1.5 \mu \mathrm{L}$ $\mathrm{MgCl} 2,10 \mu \mathrm{L}, 1 \mu \mathrm{LR}$ primer, and $1 \mu \mathrm{LF}$ primer. To detect point mutation D835 based on RFLP technique, ECORV enzyme was placed in incubator $\left(16 \mathrm{hrs}, 37^{\circ} \mathrm{C}\right)$. Marking was done in ethidium bromide, the samples were rinsed by distilled water and inspected before imagibg. The bands indicated whether there was a mutation or not. In ITD positive cases, sequencing method was used for confirmation.

For sequencing, the pieces with PCR mutation were purified using the primers and five samples were sequenced using ABI 3130 sequencing set. The diagrams were read using Chromas and the insertation mutations were spotted through comparing them with non-mutated sample sequences.

\section{Results}

Among 91 patients under study, seven patients (7.7\%) showed ITD mutation, so that out of one M0, none was observed in none them; out of three M1, one was observed in one subject; out three M2, one was observed in one subject; out of two M3, two were observed in two subjects; out of three M4, none was observed; out of two M2, none was observed among them; out of three M6, none was observed among them; out of 39 Early pre B cells, three were observed in three of them; out of 14 Pre B cell, none was observed among them; out of five B cell, none was observed in them, and out of $15 \mathrm{~T}$ cell cases, none was observed in them. (Figure 1)

As indicated by the marker in Figure 1, pieces 328 bp are observable, which are pertinent to exon 11 and 12 and intron 11 of flt 3 gene. The above samples belong to different sub-categories of FAB category and among them, column two represents AMP patients-M3; columns six and eight represent Early pre B cell patient with mutation; column nine represents patient with AML-M2; and column 13 represents AML-M1 patient. In

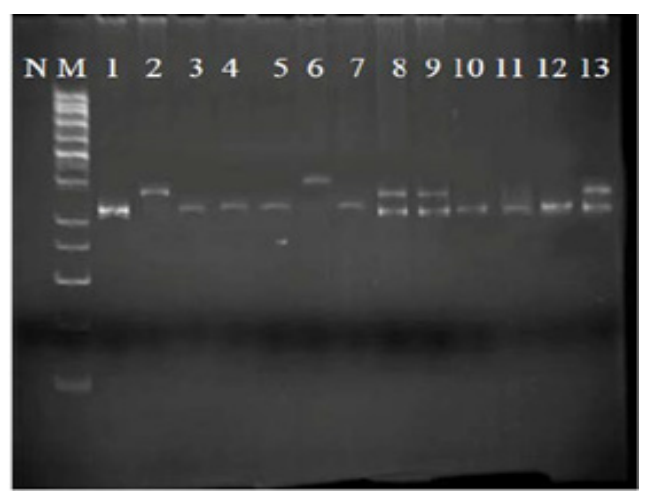

Figure 1. ITC Mutation in Flt3 Gene in Different Subgroups of Acute Leukemia Patients; N, Negative Control; M, Marker

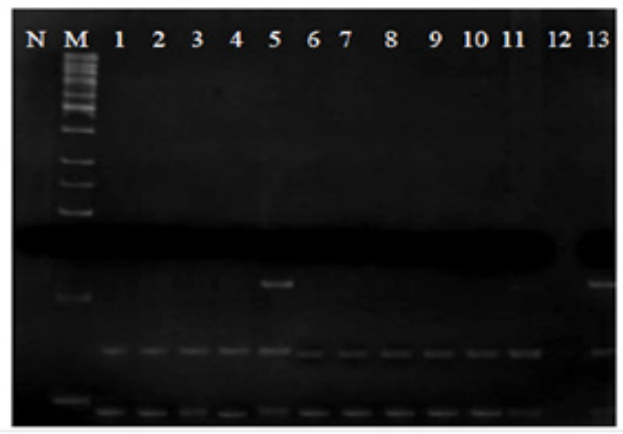

Figure 2. D835 Mutation in Flt3 Gene in Different Subgroups of AML And ALL Patients; N, Negative Control; M, Marker 
Table 2. Information of Leukemic Patients with ITD and D835 Mutations

\begin{tabular}{|c|c|c|c|c|c|}
\hline Age (year) & Gender & Disease & Karyotype & ITD & D835 \\
\hline 9 & $\mathrm{~F}$ & AML/M2 & Unknown & + & - \\
\hline 17 & $\mathrm{~F}$ & Early pre Bcell & - & - & + \\
\hline 2 & $\mathrm{~F}$ & Early pre Bcell & Normal & + & - \\
\hline 15 & M & AML/M1 & - & + & - \\
\hline 7 & M & $\mathrm{AML} / \mathrm{M} 3$ & Normal & + & - \\
\hline 13 & M & Early pre Bcel & $48, X Y,+8(\mathrm{t}(15 ; 17)(\mathrm{q} 22 ; \mathrm{q} 21),+21[15] / 46, \mathrm{XY}[5]$ & + & - \\
\hline 4 & M & AML/M3 & - & + & + \\
\hline 2 & $\mathrm{~F}$ & Early Pre Bcell & & + & - \\
\hline
\end{tabular}

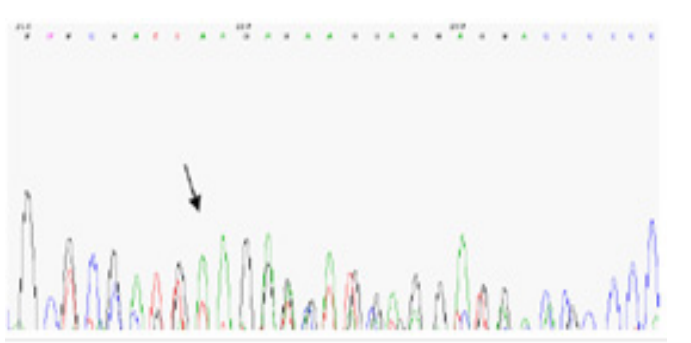

Figure 3. Results of Sequencing Leukemia Patients with ITD and D835 Mutations

all these cases, the lower band (328bp) refers to normal colon of cells and upper band $(328 \mathrm{bp}<)$ refers to leukemic mutated cell colon, where translocation and duplication happen in internal sequence of exon 11 and 12 and intron 11 and length of this region exceeds $328 \mathrm{bp}$.

Among 91 ALL and AML patients, two had point mutation D835 one at M3 and one at Pre B cell (ALL).

Figures illustrates PCR products of exon 17 of flt 3 gene where ECORV enzyme is added through RFLP technique. Clearly, DNA break is observed in all specimens except for columns No.5 and 13 where DNA breakpoint is not observed in some of the products. In fact, pieces $114 \mathrm{bp}$ of PCR products that are broken into $68 \mathrm{pb}$ and 46bp show that no mutation has occurred in these specimen. Moreover, breakpoint of the enzyme GAT 5'... ATC...3' is intact and it can easily break PCR products to smaller pieces. However, different bands are observed in the patients No. 13 and 5 so that the upper band is the $114 \mathrm{bp}$ band in which breakpoint of the enzyme is changed due to point mutation and the enzyme is not capable to break the DNA. This indicates point mutation D835. The two lower bands (i.e.68bp and 46bp) are cell's normal colon in ALL and AML patients without mutation. Table 1 lists information of eight patients who demonstrated the mutations.

Out of seven gene samples with ITD mutation, four samples were sequenced for further examinations and different results were obtained. Nucleotide insertions 27, 27, 47, and 63 were observed. Samples No.39 showed nucleotide insertion 63, sample No.53 showed nucleotide insertion 27, sample No. 83 showed nucleotide insertion No. 27, and sample No.83 showed nucleotide insertion 47. Figure 3 illustrates sequencing results in sample No. 83 noted by an arrow, which indicates initiation point of the mutation (Figure 3).

\section{Discussion}

ITD mutation was observed in seven patients (7.7\% of the study group) with acute leukemia and 2 patients $(2.2 \%)$ showed point mutation D835 so that distribution of them in different FAB subgroups was not identical. Positive cases of ITD mutation was observed in M1, M2, M3, and Early pre B cell.

The mutation under study is highly important for leukemia pathogens. Mutation in flt 3 receptor belonged to RTKII and induced uncontrolled proliferation of leukemia cells. Studies with larger sample groups have reported ITD mutation with bad prognosis and development of leukemia that resists standard treatments [15].

Bad prognosis has been reported by three studies on children with AML and flt3 mutation. The study with largest sample group $(\mathrm{n}=91)$ by CCG group reported 15 cases of flt3/ITD mutation in 91 AML patients (16.5\%). Regress of the disease in flt $3 /$ ITD + and flt $3 /$ ITD + patients was $40 \%$ and $73 \%$ respectively $(p=0.005)$. Event free survival (EFS) of eight years was reported in $7 \%$ and $44 \%$ of flt $3 /$ ITD + and flt $3 /$ ITD + patients respectively $(p$ $=0.002$ ). Highest frequency was observed in the subgroup M3. Flt3/ITD mutation in adults usually refers to a bad prognosis [14-17].

The results showed flt $3 /$ ITD mutations in $23.5 \%$ of AML and $4 \%$ of ALL children. Regardless of number of insertion or duplicate nucleotide, presence of amino acid of whatever number causes spatial deformation of the protein so that preventive effect of JM region on auto-phosphorylation fades away. The duplications can occur in exon 11 and 12 and intron 11 of flt 3 gene to be inserted in the common border of exon and intron 11 [15-18]. Point mutation in exon 17 of flt 3 receptor gene was also examined, where aspartic acid 835 - amino acid (D835) is substituted by other amino acids such as tyrosine, valine, etc.. The substitution leads to development of activation loop. Among 91 patients with acute leukemia, two patients demonstrated the mutation, which was AML in $6 \%$ of the cases and ALL in $1.4 \%$ of the cases. Due to low rate of the mutation and since the sample group was small, it is not possible to define a relationship between the mutation and FAB subcategories. A study reported ASP835 substitution in 30 subjects among 429 AML children (7\%), one subject among 29 MDS patients (3\%), and one subject among 36 ALL patients (3\%). A similar study reported the mutation in seven subjects among 35 
AML patients (7\%).

Occurrence of point mutation D835 was significantly less than ITD mutation in flt3 gene; while the both mutations were highly frequent in AML. Both ITD and D835 mutations in flt3 gene were reported in a patient; however sequencing studies have shown that these two mutations were not on the same allele.

Here, ITD mutation was observed in $7.7 \%$ of the patients without identical distribution among FAB subcategories for leukemia categorization. As suggest by studies, flt3/ITD mutation has been observed in 10-20\% of the children with AML and 1-5\% with ALL. In general, the mutation was significantly associated with weak emergence and bad prognosis in ALL and AML patients.

As to point mutation D in flt 3 gene, $4 \%$ of the ALL and AML patients demonstrated such a mutation. This figure in other studies is reported $5 \%$ with different distribution in different FAB subcategories. Effective follow up of ITD and D835 mutation in flt 3 receptor gene and carrying out molecule diagnosis as a routine procedure will lead to better decisions as to treatment of AML and ALL and avoid development of resistance and frequent recurrences.

\section{Acknowledgements}

The authors wish to thank their colleagues in the Department of Hematology, and Molecule/Cell Research Center, Iran University of Medical Science.

\section{References}

1. Y D. Experimental study of apoptosis induced by infectious bursal disease virus using Tunel assay and electron microscope [dissertation]. Tehran, : Tehran University 2004.

2. Hablolvarid MH SHI, Pourbakhsk SA, Gholami MR. A study on Histopathologic changes in chicken following intravenous inoculation with avian influenza virus A/ chicken/Iran/1988(H9N2). Archives of Razi Institute, 2003;55,:41-51.

3. Barber GN. Host defense, viruses and apoptosis. Cell death and differentiation. 2001;8(2):113-26.

4. Frankfurt OS, Krishan A. Identification of apoptotic cells by formamide-induced dna denaturation in condensed chromatin. The journal of histochemistry and cytochemistry : official journal of the Histochemistry Society. 2001;49(3):369-78.

5. Ito T, Kobayashi Y, Morita T, Horimoto T, Kawaoka Y. Virulent influenza A viruses induce apoptosis in chickens. Virus research. 2002;84(1-2):27-35.

6. Kwon YK, Joh SJ, Kim MC, Sung HW, Lee YJ, Choi JG, et al. Highly pathogenic avian influenza (H5N1) in the commercial domestic ducks of South Korea. Avian pathology : journal of the WVPA. 2005;34(4):367-70.

7. Kunio O MN, Bo Y, Toshio B, Toshio Y. Apoptosis induced by influenza virus-hemagglutin stimulation may be related to fluctuation of cellular oxidative condition. Biol Pharmacol Bull,. 2003;26,:141-7.

8. Liu J, Okazaki K, Ozaki H, Sakoda Y, Wu Q, Chen F, et al. H9N2 influenza viruses prevalent in poultry in China are phylogenetically distinct from A/quail/Hong Kong/G1/97 presumed to be the donor of the internal protein genes of the H5N1 Hong Kong/97 virus. Avian pathology : journal of the WVPA. 2003;32(5):551-60.
9. Morris J NS, Harry S, Clive S. Influenza A virus induced apoptosis is a multifactorial process: Exploiting reverse genetics to elucidate the role of influenza A virus proteins in virus . induced apoptosis. Virology, 2005. 198-211. p.

10. Perkins LE, Swayne DE. Varied pathogenicity of a Hong Kong-origin H5N1 avian influenza virus in four passerine species and budgerigars. Veterinary pathology. 2003;40(1):14-24.

11. Roberto P EA, Moises F, Luis P. Avian influenza: Histopathology and viral detection in formalin-fixed paraffin-embedded tissue by RT-PCR. Vet Med, 2004. , 1-9. p.

12. Shalaby AA, Slemons RD, Swayne DE. Pathological studies of A/chicken/Alabama/7395/75 (H4N8) influenza virus in specific-pathogen-free laying hens. Avian diseases. 1994;38(1):22-32.

13. Swayne DE, Slemons RD. Comparative pathology of intravenously inoculated wild duck- and turkey-origin type A influenza viruses in chickens. Avian diseases. 1995;39(1):74-84.

14. Takizawa T. [Influenza virus infection and apoptosis]. Nihon rinsho Japanese journal of clinical medicine. 2003;61(11):2001-5.

15. To KF, Chan PK, Chan KF, Lee WK, Lam WY, Wong KF, et al. Pathology of fatal human infection associated with avian influenza A H5N1 virus. Journal of medical virology. 2001;63(3):242-6.

16. Uiprasertkul M, Kitphati R, Puthavathana P, Kriwong $\mathrm{R}$, Kongchanagul A, Ungchusak K, et al. Apoptosis and pathogenesis of avian influenza A (H5N1) virus in humans. Emerging infectious diseases. 2007;13(5):708-12.

17. Zhirnov OP, Ksenofontov AL, Kuzmina SG, Klenk HD. Interaction of influenza A virus M1 matrix protein with caspases. Biochemistry Biokhimiia. 2002;67(5):534-9.

18. Zhou J LH, Cheung CY, Ng IH, Peiris JS, Lau YL. Functional tumor necrosis factor-related apoptosis inducing ligand production by avian influenza virus-infected macrophages. . J Infect Dis,. 2006; 193,:945-53.

This work is licensed under a Creative Commons AttributionNon Commercial 4.0 International License. 